\title{
Diet-dependent acid load and type 2 diabetes: pooled results from three prospective cohort studies
}

\author{
Jessica C. Kiefte-de Jong ${ }^{1,2,3} \cdot$ Yanping $\mathrm{Li}^{3} \cdot \mathrm{Mu} \mathrm{Chen}^{3,4}$ • Gary C. Curhan ${ }^{4}$ • \\ Josiemer Mattei $^{3}$ - Vasanti S. Malik ${ }^{3} \cdot$ John P. Forman $^{5}$ • Oscar H. Franco ${ }^{1}$. \\ Frank B. $\mathrm{Hu}^{3,4,5}$
}

Received: 4 June 2016 / Accepted: 17 October 2016 / Published online: 17 November 2016

(C) The Author(s) 2016. This article is published with open access at Springerlink.com

\begin{abstract}
Aims/hypothesis Studies suggest a potential link between low-grade metabolic acidosis and type 2 diabetes. A western dietary pattern increases daily acid load but the association between diet-dependent acid load and type 2 diabetes is still unclear. This study aimed to assess whether diet-dependent acid load is associated with the risk of type 2 diabetes.

Methods We examined the association between energyadjusted net endogenous acid production (NEAP), potential renal acid load (PRAL) and animal protein-to-potassium ratio (A:P) on incident type 2 diabetes in 67,433 women from the Nurses' Health Study, 84,310 women from the Nurses' Health Study II and 35,743 men from the Health Professionals' Follow-up Study who were free from type 2 diabetes, cardiovascular disease and cancer at baseline. Study-specific HRs were estimated using Cox proportional hazards models with
\end{abstract}

Electronic supplementary material The online version of this article (doi:10.1007/s00125-016-4153-7) contains peer-reviewed but unedited supplementary material, which is available to authorised users.

Jessica C. Kiefte-de Jong

j.c.kiefte-dejong@erasmusmc.nl

1 Department of Epidemiology, Erasmus MC, Room NA2903, PO Box 2040, 3000, CA Rotterdam, the Netherlands

2 Department of Global Public Health, Leiden University College, The Hague, the Netherlands

3 Department of Nutrition, Harvard T. H. Chan School of Public Health, Boston, MA, USA

4 Department of Epidemiology, Harvard T. H. Chan School of Public Health, Boston, MA, USA

5 Channing Division of Network Medicine, Department of Medicine, Brigham and Women's Hospital, Harvard Medical School, Boston, MA, USA time-varying covariates and were pooled using a random effects meta-analysis.

Results We documented 15,305 cases of type 2 diabetes during 4,025,131 person-years of follow-up. After adjustment for diabetes risk factors, dietary NEAP, PRAL and A:P were positively associated with type 2 diabetes (pooled HR [95\% CI] for highest (Q5) vs lowest quintile (Q1): 1.29 [1.22, 1.37], $p_{\text {trend }}<0.0001 ; 1.29[1.22,1.36], p_{\text {trend }}<0.0001$ and 1.32 $[1.24,1.40], p_{\text {trend }}<0.0001$ for NEAP, PRAL and A:P, respectively). These results were not fully explained by other dietary factors including glycaemic load and dietary quality (HR [95\% CI] for Q5 vs Q1: $1.21[1.09,1.33], p_{\text {trend }}<0.0001$; $1.19[1.08,1.30]$ and $1.26[1.17,1.36], p_{\text {trend }}<0.0001$ for NEAP, PRAL and A:P, respectively).

Conclusions/interpretation This study suggests that higher diet-dependent acid load is associated with an increased risk of type 2 diabetes. This association is not fully explained by diabetes risk factors and overall diet quality.

Keywords Acid-base balance $\cdot$ Dietary acid load $\cdot$ Glucose intolerance $\cdot$ Insulin resistance

$\begin{array}{ll}\text { Abbreviations } \\ \text { AHEI } & \text { Alternative Healthy Eating Index } \\ \text { A:P } & \text { Animal protein-to-potassium ratio } \\ \text { FFQ } & \text { Food frequency questionnaire } \\ \text { HPFS } & \text { Health Professionals' Follow-up Study } \\ \text { MET } & \text { Metabolic equivalent task } \\ \text { NEAP } & \text { Net endogenous acid production } \\ \text { NHS } & \text { Nurses' Health Study } \\ \text { NHS2 } & \text { Nurses' Health Study II } \\ \text { PRAL } & \text { Potential renal acid load }\end{array}$




\section{Introduction}

Type 2 diabetes is an important cause of mortality and morbidity globally and its increasing prevalence is driven by the obesity epidemic and ageing populations [1]. A western dietary pattern, characterised by high intake of foods containing animal products and beverages containing sugar and low intake of fruit, vegetables and whole grains, is associated with an increased risk of type 2 diabetes [2]. This association can be partially explained by low intake of whole grains and poor dietary fat quality, which have been related to glucose homeostasis in both experimental $[3,4]$ and observational studies [1, 2]. However, potential mechanisms behind other components of a western dietary pattern, such as foods rich in animal protein, are not yet fully elucidated.

It has been hypothesised that a western-style diet may cause low-grade metabolic acidosis, possibly leading to metabolic disturbances $[5,6]$. Sulphur-containing amino acids (e.g. methionine and cysteine) are found in animal proteins, particularly in meat and fish, and are important determinants of dietary acid load due to sulfate generation after their oxidation [5]. Indeed, several studies have shown that the positive association between protein intake and type 2 diabetes is mainly driven by animal protein intake [7, 8].

Physiological effects of high dietary acid load include increased urinary excretion of sulfate, phosphorus and chloride, increased elimination of calcium, intrarenal vasodilatation and increased glomerular filtration rate $[5,9]$. Hence, dietary acid load has been studied extensively in relation to kidney disease $[10,11]$, blood pressure $[12,13]$ and bone health [14]. Dietary acid load may also play a role in glucose homeostasis. Associations between markers of metabolic acidosis (i.e. low serum bicarbonate, higher anion gap and low urine $\mathrm{pH}$ ) and insulin resistance have been reported in individuals with insulin resistance [15] and in a nested case-control study in type 2 diabetes [16]. In addition, a recent study found that dietary acid load was associated with insulin resistance in healthy Japanese workers [17]. The E3N-EPIC cohort study found diet-dependent acid load to be associated with an increased risk of type 2 diabetes [18]. However, this was not confirmed in a cohort of community-dwelling men in Sweden [19] and a Japanese cohort study only found an association between dietary acid load and type 2 diabetes risk in younger men [20]. These contrasting findings may be explained by differences in other dietary habits, sex, age and other population characteristics. Therefore, further research on this topic is needed to replicate and validate previous findings and facilitate dietary recommendations related to diet-dependent acid load for public health purposes. We aimed to evaluate the prospective association between dietary acid load and the incidence of type 2 diabetes in three cohorts of adults in the USA.

\section{Methods}

Study population Data was used from three prospective cohort studies of health professionals in the USA: the Nurses' Health Study (NHS), Nurses' Health Study II (NHS2) and the Health Professionals' Follow-up Study (HPFS).

The NHS was established in 1976 and included 121,700 registered nurses aged 30-55 years living in the 11 most populous states of the USA (California, Connecticut, Florida, Maryland, Massachusetts, Michigan, New Jersey, New York, Ohio, Pennsylvania and Texas). NHS2 was established in 1989 and included a younger population of nurses. The NHS2 population included 116,430 women between the ages of 25 and 42 years. The HPFS began in 1986 and included 51,529 men in health professions aged $40-75$ years $(29,683$ dentists, 4185 pharmacists, 3745 optometrists, 2220 osteopath physicians, 1600 podiatrists and 10,098 veterinarians).

At baseline and every 2 years, participants in the NHS, NHS2 and HPFS completed questionnaires about diseases and healthrelated topics such as smoking, physical activity and medication use. In addition, food frequency questionnaires (FFQs) to assess dietary intake were administered at 4 year intervals. The followup rate was greater than $90 \%$ in all cohorts.

For the present analyses we excluded participants with prior diagnosis at baseline of cardiovascular disease (including coronary heart disease and stroke), cancer, type 1 or type 2 diabetes or history of gestational diabetes (in NHS cohorts only). Additionally, we excluded participants with implausible daily intakes of total energy $(<2510 \mathrm{~kJ}$ or $>14,644 \mathrm{~kJ}$ for women and $<3347 \mathrm{~kJ}$ or $>17,573 \mathrm{~kJ}$ for men) and participants with missing FFQ data. The final population of analyses consisted of 67,433 women in the NHS, 84,310 women in the NHS2 and 35,743 men in the HPFS.

The study protocols were approved by the institutional review board of Brigham and Women's Hospital and Harvard T. H. Chan School of Public Health and all participants provided informed consent.

Dietary assessment and dietary acid load Habitual dietary intake over the preceding year was assessed by validated FFQs described in detail previously [21, 22]. Dietary data were collected in 1984 for the NHS, 1986 for the HPFS and 1991 for the NHS2 and were updated every 4 years with similar FFQs.

For each food item, participants were asked how often on average they consumed a serving of that food. The frequency of a food item was recorded as number of times per day, week or month.

To calculate nutrient intake, the frequency of consumption of each food item was multiplied by the nutrient content of one serving and then summed across all food items. Nutrient values of foods were obtained from the US Department of Agriculture [23]. 
We calculated dietary acid load by using three previously defined algorithms: net endogenous acid production (NEAP) [24], potential renal acid load (PRAL) [25] and animal protein-to-potassium ratio (A:P) [26]:

$\operatorname{NEAP}(\mathrm{mEq} /$ day $)=(54.5 \times \operatorname{protein}[\mathrm{g} /$ day $] / \operatorname{potassium}[\mathrm{mEq} /$ day $])-10.2$

$\operatorname{PRAL}(\mathrm{mEq} /$ day $)=0.4888 \times$ protein $[\mathrm{g} /$ day $]+0.0366$

$$
\begin{aligned}
& \times \text { phosphorus }[\mathrm{mg} / \text { day }]-0.0205 \\
& \times \text { potassium }[\mathrm{mg} / \text { day }]-0.0125 \times \text { calcium }[\mathrm{mg} / \text { day }] \\
& -0.0263 \times \text { magnesium }[\mathrm{mg} / \text { day }]
\end{aligned}
$$

$\mathrm{A}: \mathrm{P}=$ animal protein $(\mathrm{g} /$ day $) /$ potassium $(\mathrm{g} /$ day $)$

The NEAP algorithm by Frassetto et al [24] estimates dietary acid load from an acid precursor (dietary protein) and an index of base precursors from organic anions (potassium) and has been previously validated in healthy men and women aged 17-73 years [24]. NEAP only includes protein and potassium as $\mathrm{pH}$-altering nutrients from diet whereas the PRAL algorithm by Remer and Manz [25] estimates dietary acid load taking into account average intestinal absorption rates of ingested protein and additional minerals and has been validated against urine $\mathrm{pH}$ in healthy adults [25]. Since it is considered that animal protein constitutes a major determinant of dietary acid load [27], and NEAP and PRAL do not make a distinction between animal and vegetable protein, we also assessed the ratio of animal protein to potassium, as described previously [26].

To account for measurement error and to remove extraneous variation arising from total energy intake, all nutrients (including those for NEAP, PRAL and A:P) were adjusted for total energy intake by using the residual method [28].

The FFQs were validated against the diet records of 173 participants in the NHS in 1980 and 127 participants in the HPFS in 1986 [21, 22]. Correlation coefficients adjusted for energy and within-person variation varied from 0.52 (NHS) to 0.44 (HPFS) for total protein, from 0.53 (NHS) to 0.73 (HPFS) for potassium, from 0.51 (NHS) to 0.54 (HPFS) for calcium, from 0.53 (NHS) to 0.57 (HPFS) for phosphorus and 0.72 for magnesium when compared with 1 week food records $[21,22]$.

Assessment of type 2 diabetes Every 2 years, participants in all three cohorts were asked whether they had any physician diagnosis of diabetes. Participants who reported physiciandiagnosed diabetes were sent a supplementary questionnaire to obtain information about symptoms, diagnostic tests and diabetes drug use.

Participants were originally defined as having type 2 diabetes if they experienced one or more symptoms of polydipsia, polyuria, weight loss and hunger and met at least one of the following criteria [29]: increased blood glucose levels (fasting levels $\geq 7.8 \mathrm{mmol} / 1$, random blood levels $\geq 11.1 \mathrm{mmol} / 1$ and/or $2 \mathrm{~h}$ blood glucose levels $\geq 11.1 \mathrm{mmol} / 1$ during OGTT); raised blood glucose levels on two different occasions in the absence of symptoms; or treatment with glucose-lowering drugs.

In June 1998 the diagnostic criteria of type 2 diabetes were changed and a fasting blood glucose level of $7 \mathrm{mmol} / \mathrm{l}$, rather than $7.8 \mathrm{mmol} / \mathrm{l}$, was used as the threshold for diagnosis [30]. The questionnaires for the diagnosis of type 2 diabetes have been previously validated in subsamples of the cohorts [31, 32]. These validation studies showed that $98 \%$ and $97 \%$ of the cases of self-reported type 2 diabetes were confirmed by medical records in the NHS [32] and the HPFS, respectively [31,32].

Covariates Updated information on anthropometric and lifestyle factors for type 2 diabetes, including body weight (height was ascertained at baseline), cigarette smoking, physical activity, family history of diabetes and history of kidney stones was collected in the 2-yearly questionnaires. Among participants in the NHS and NHS2, menopausal status and postmenopausal hormone use was ascertained by questionnaires; oral contraceptive use was ascertained by questionnaire in the NHS2 only. An approximation of moderate/vigorous physical activity levels was determined by multiplying the metabolic equivalent tasks (METs) measured in hours per week of each activity by the number of hours spent on the activity and taking the sum of these values (six METs or greater was defined as moderate/vigorous activity).

Based on the FFQ, an adherence score for the Alternative Healthy Eating Index (AHEI), an indicator of adherence to healthy eating behaviour, was derived as described in detail elsewhere [33], as well as indices of glycaemic load. Briefly, the AHEI included intake of the following foods and nutrients: vegetables, fruits, whole grains, sugar-sweetened beverages and fruit juice, nuts and legumes, red and processed meat, trans fat, longchain $n$-3 fat, polyunsaturated fat and sodium. Alcohol intake was excluded from the AHEI and treated as an individual covariate. Each component was scored on a scale of $0-10$ and the overall score ranged from $0-100$, with a higher score representing a healthier diet. Principal component analysis was used for a posteriori-derived western-like dietary pattern scores as described in detail previously [34]. The overall glycaemic load was calculated by taking the sum of the following product: carbohydrates per food item $\times$ glycaemic index of food item $\times$ mean servings of food item per day [35]. 
Statistical analyses To assess long-term dietary acid load exposure and to reduce within-person variation, we calculated the cumulative average of dietary acid load from baseline until type 2 diabetes diagnosis, death or end of follow-up, whichever came first. Missing dietary data on follow-up visits were replaced by the cumulative average of prior dietary assessments.

Participant characteristics by dietary acid load were standardised to the age distribution of the study population.

We used multivariable Cox proportional hazard models with time-dependent covariates to assess the relationship between quintiles of NEAP, PRAL and A:P and type 2 diabetes. Linear trends across the quintiles were examined by using the median values of each quintile of dietary acid load as continuous variable in the analyses.

To account for differences in age distribution, timedependent Cox regression analyses were stratified by age in months (i.e. an age-adjusted model allowing for different baseline hazard functions for different age groups).

Results were further adjusted for total energy intake (quintiles), BMI (continuously), family history of type 2 diabetes (yes/no), menopausal status (premenopausal, postmenopausal without hormone use, postmenopausal with past hormone use, postmenopausal with current hormone use), history of hypertension and hypercholesterolaemia (yes/no), smoking status (never smoking, former smoker, current smoker [1-14 cigarettes, $15-24$ cigarettes and $\geq 25$ cigarettes/day]), alcohol intake $(0,0.1-4.9,5.0-14.9,15.0-19.9,20.0-29.9$ and $\geq 30 \mathrm{~g} /$ day) and moderate/vigorous physical activity $(0,0.01-1.0,1.0-3.5,3.5-6.0$ and $\geq 6.0 \mathrm{~h} /$ week) (multivariate model 1). Additionally we adjusted the analyses for other dietary exposures associated with type 2 diabetes [1, 2] such as glycaemic load (quintiles), AHEI (quintiles) and the western dietary pattern (quintiles) (multivariate model 2).

Sensitivity analyses were performed by stratification according to BMI status $\left(<25 \mathrm{~kg} / \mathrm{m}^{2}, 25-29 \mathrm{~kg} / \mathrm{m}^{2}\right.$ and $\left.\geq 30 \mathrm{~kg} / \mathrm{m}^{2}\right)$, age $(<60$ years and $\geq 60$ years), smoking status (ever vs never smoker), presence of hypertension and history of kidney stones [34]. Effect modification by BMI, smoking status, hypertension and kidney stones was evaluated by using the likelihood ratio test. Furthermore, since it has recently been found that animal protein but not vegetable protein was associated with an increased risk of type 2 diabetes [8], we additionally adjusted the association between NEAP and type 2 diabetes for animal protein intake (quintiles). Last, to assess the potential influence of dietary changes due to diabetesrelated symptoms before diagnosis, we used a 4 year lag between dietary acid load and type 2 diabetes in sensitivity analysis. Results from the three cohorts were pooled using random effects meta-analysis and are reported as HR and 95\% CI. All analyses were performed with SAS 9.3 Unix
(SAS Institute, Cary, NC, USA). A $p$ value $<0.05$ was considered as statistically significant.

\section{Results}

Characteristics of the study population Mean (SD) dietary NEAP, PRAL and A:P was, respectively, 43.8 (8.7) mEq/day, $-3.1(10.6) \mathrm{mEq} /$ day and 18.4 (4.1) for the NHS, 49.9 (10.5) $\mathrm{mEq} /$ day, $6.4(12.2) \mathrm{mEq} /$ day and 20.3 (5.1) for the NHS2 and $47.7(10.5) \mathrm{mEq} /$ day, $5.7(13.2) \mathrm{mEq} /$ day and 19.5 (5.1) for the HPFS.

Participants with high dietary NEAP tended to consume more red meat and fish and to consume fruit, whole grains and sugar-containing beverages less often. In addition, participants with high dietary NEAP were likely to consume less alcohol and had an overall lower AHEI score and a higher western dietary pattern score (Table 1).

During 1,709,638 person-years of follow-up, 7655 new cases with type 2 diabetes were ascertained in the NHS; during 1,513,932 person-years of follow-up, 4109 cases were ascertained in the NHS2 and during 801,561 person-years of follow-up 3541 cases were ascertained in HPFS.

Dietary acid load and type 2 diabetes The association between indices of dietary acid load and type 2 diabetes is shown in Table 2. In the NHS and HPFS cohorts, dietary NEAP was associated with an increased risk of type 2 diabetes after adjustment for diabetes risk factors (HR $[95 \% \mathrm{CI}]$ for highest vs lowest quintile of NEAP was $1.28[1.18,1.38], p_{\text {trend }}<0.0001$ for NHS, 1.30 $[1.17,1.44], p_{\text {trend }}<0.0001$ for NHS2 and 1.32 [1.18, $1.47], p_{\text {trend }}<0.0001$ for HPFS).

Similar results were found for PRAL. Higher PRAL was associated with an increased risk of type 2 diabetes after adjustment for diabetes risk factors ( $\mathrm{HR}[95 \% \mathrm{CI}]$ for highest vs lowest quintile was $1.26[1.16,1.36], p_{\text {trend }}<0.0001$ for NHS, $1.33[1.20,1.48], p_{\text {trend }}<0.0001$ for NHS2 and $1.29[1.16$, $1.44], p_{\text {trend }}<0.0001$ for HPFS).

In addition, a higher A:P was associated with an increased risk of type 2 diabetes after adjustment for diabetes risk factors (HR [95\% CI] for highest vs lowest quintile was 1.26 [1.16, $1.36], p_{\text {trend }}<0.0001$ for NHS, $1.35[1.21,1.50], p_{\text {trend }}$ $<0.0001$ for NHS2 and 1.39 [1.25, 1.55], $p_{\text {trend }}<0.0001$ for HPFS). Additional adjustment for dietary risk factors for type 2 diabetes attenuated some of the associations but they remained statistically significant except for PRAL in HPFS (HR [95\% CI] for highest vs lowest quintile of NEAP was $1.29[1.19,1.41], p_{\text {trend }}<0.0001$ for NHS, 1.22 [1.09, 1.37], $p_{\text {trend }}<0.0001$ for NHS2 and $1.09[0.96,1.23], p_{\text {trend }}=0.0370$ for HPFS and HR [95\% CI] for PRAL was 1.23 [1.13, 1.33], $p_{\text {trend }}<0.0001$ for NHS, $1.25[1.12,1.40], p_{\text {trend }}<0.0001$ for NHS2 and $1.07[0.94,1.20], p_{\text {trend }}=0.358$ for HPFS; Table 2 ). 
Table 1 Age-adjusted characteristics of the NHS and HPFS at median follow-up time

\begin{tabular}{|c|c|c|c|c|c|c|}
\hline \multirow[t]{2}{*}{ Characteristic } & \multicolumn{2}{|l|}{ NHS (1994) ${ }^{\mathrm{a}}$} & \multicolumn{2}{|c|}{ NHS2 (1999) ${ }^{\mathrm{a}}$} & \multicolumn{2}{|l|}{ HPFS $(1996)^{\mathrm{a}}$} \\
\hline & $\begin{array}{l}\text { Quintile 1 } \\
(n=11,449)\end{array}$ & $\begin{array}{l}\text { Quintile } 5 \\
(n=14,974)\end{array}$ & $\begin{array}{l}\text { Quintile 1 } \\
(n=18,030)\end{array}$ & $\begin{array}{l}\text { Quintile } 5 \\
(n=13,878)\end{array}$ & $\begin{array}{l}\text { Quintile 1 } \\
(n=6428)\end{array}$ & $\begin{array}{l}\text { Quintile } 5 \\
(n=7472)\end{array}$ \\
\hline Age, years ${ }^{b}$ & $62.4(6.8)$ & $57.6(6.8)$ & $45.1(4.5)$ & $43.4(4.7)$ & $64.6(9.4)$ & $59.5(8.4)$ \\
\hline Premenopausal, \% & 10.2 & 11.0 & 74.1 & 70.5 & - & - \\
\hline Family history of diabetes, $\%$ & 17.3 & 19.1 & 14.9 & 17.4 & 19.1 & 20.2 \\
\hline BMI, $\mathrm{kg} / \mathrm{m}^{2}$ & $24.9(4.4)$ & $27.3(5.6)$ & $24.8(5.0)$ & $28.0(6.9)$ & $25.4(3.5)$ & $26.5(3.9)$ \\
\hline Hypertension, \% & 21.3 & 24.4 & 9.3 & 15.2 & 35.6 & 36.6 \\
\hline Hypercholesterolaemia, \% & 27.7 & 30.1 & 18.6 & 24.6 & 41.0 & 43.4 \\
\hline Moderate/vigorous intensity activity, $\mathrm{h} /$ week & $2.6(4.1)$ & $1.5(3.0)$ & $3.0(4.0)$ & $1.7(2.8)$ & $5.0(6.4)$ & $3.1(5.0)$ \\
\hline Current smoker, $\%$ & 14.2 & 13.0 & 10.1 & 8.5 & 4.4 & 7.1 \\
\hline Alcohol intake, g/day & $5.8(10.1)$ & $4.5(9.1)$ & $5.0(8.3)$ & $2.7(6.4)$ & $11.8(15.8)$ & $9.7(14.0)$ \\
\hline AHEI score & $50.6(10.1)$ & $45.0(9.8)$ & $50.1(9.5)$ & $41.3(8.5)$ & $53.0(9.0)$ & $44.0(9.3)$ \\
\hline Western dietary pattern score & $0.4(0.9)$ & $0.6(0.8)$ & $-0.3(0.7)$ & $0.1(0.8)$ & $-0.4(0.7)$ & $0.2(1.0)$ \\
\hline Glycaemic load, units/day & $113.5(16.8)$ & $95.6(15.7)$ & $134.5(18.6)$ & $114.2(19.5)$ & $145.6(23.9)$ & $117.5(22.3)$ \\
\hline Red meat intake, no. of servings/day & $0.8(0.5)$ & $1.1(0.6)$ & $0.6(0.4)$ & $1.2(0.6)$ & $0.7(0.5)$ & $1.4(0.9)$ \\
\hline Sugar-containing beverage intake, no. of servings/day & $1.5(0.9)$ & $0.9(0.6)$ & $1.4(1.2)$ & $0.9(1.0)$ & $1.5(1.2)$ & $1.0(0.8)$ \\
\hline Dairy intake, no. of servings/day & $1.6(0.9)$ & $1.4(0.8)$ & $2.3(1.3)$ & $1.8(1.1)$ & $1.9(1.3)$ & $1.7(1.2)$ \\
\hline Vegetable intake, no. of servings/day & $4.3(1.7)$ & $3.4(1.2)$ & $3.9(2.0)$ & $2.3(1.1)$ & $3.9(2.0)$ & $2.4(1.2)$ \\
\hline Nut intake, no. of servings/day & $1.2(0.8)$ & $0.8(0.6)$ & $0.4(0.4)$ & $0.2(0.2)$ & $0.6(0.5)$ & $0.4(0.4)$ \\
\hline Fruit intake, no. of servings/day & $1.7(1.0)$ & $0.8(0.5)$ & $1.8(1.1)$ & $0.7(0.5)$ & $2.6(1.6)$ & $1.0(0.7)$ \\
\hline Whole grain intake, $g /$ day & $15.4(10.4)$ & $11.1(7.9)$ & $28.3(15.9)$ & $18.2(11.8)$ & $32.3(20.1)$ & $20.3(15.5)$ \\
\hline Fish intake, no. of servings/day & $0.2(0.2)$ & $0.3(0.2)$ & $0.2(0.2)$ & $0.2(0.2)$ & $0.3(0.3)$ & $0.4(0.3)$ \\
\hline Energy intake, $\mathrm{kJ} /$ day & $7196(2192)$ & $6987(2205)$ & $7510(2025)$ & $7234(2058)$ & $8284(2251)$ & $2029(1017)$ \\
\hline Fat intake, $\%$ of energy & $29.0(4.9)$ & $34.7(4.6)$ & $27.5(5.0)$ & $34.0(5.1)$ & $26.7(5.5)$ & $34.2(5.3)$ \\
\hline Saturated fat intake, $\%$ of energy & $10.1(2.2)$ & $12.2(2.1)$ & $9.3(2.1)$ & $11.9(2.2)$ & $8.6(2.3)$ & $11.7(2.4)$ \\
\hline Polyunsaturated fat intake, $\%$ of energy & $4.5(1.3)$ & $4.9(1.2)$ & $5.1(1.2)$ & $5.7(1.2)$ & $5.3(1.4)$ & $5.9(1.2)$ \\
\hline Carbohydrate intake, $\%$ of energy & $54.5(6.6)$ & $44.8(6.1)$ & $56.4(6.3)$ & $45.8(6.4)$ & $55.6(7.6)$ & $43.5(6.8)$ \\
\hline Protein intake, $\%$ of energy & $16.6(2.3)$ & $19.8(2.9)$ & $17.0(2.5)$ & $20.4(3.1)$ & $16.3(2.4)$ & $20.0(3.1)$ \\
\hline Animal protein intake, $\%$ of energy & $11.1(2.5)$ & $15.1(2.9)$ & $11.0(2.8)$ & $15.7(3.0)$ & $10.4(2.6)$ & $15.3(3.1)$ \\
\hline Potassium intake, mg/day & $3583(930)$ & $2673(688)$ & 3449 (941) & 2449 (708) & $3875(1060)$ & $2805(802)$ \\
\hline Dietary NEAP, mEq/day & $32.1(3.5)$ & $55.7(6.0)$ & $36.8(4.5)$ & $66.7(7.3)$ & $33.8(4.4)$ & $62.5(7.4)$ \\
\hline Dietary PRAL, mEq/day & $-17.4(8.0)$ & $8.7(6.4)$ & $-8.8(9.1)$ & $22.0(7.3)$ & $-12.9(10.3)$ & $21.3(7.2)$ \\
\hline Dietary A:P & $13.2(2.2)$ & $23.5(3.0)$ & $14.3(3.0)$ & $27.8(3.8)$ & $13.2(2.8)$ & $26.1(3.9)$ \\
\hline
\end{tabular}

Values are expressed as means (SD) or \%, standardised to the age distribution of the study population and grouped according to quintiles of NEAP (quintile 1, low; quintile 5, high)

${ }^{a}$ Year represents median follow-up

${ }^{\mathrm{b}}$ Value is not age-adjusted

The pooled estimate of HR ( $95 \%$ CI) for type 2 diabetes risk according to dietary NEAP, PRAL and A:P was 1.21 $(1.09,1.33), p_{\text {trend }}<0.0001,1.19(1.08,1.30) p_{\text {trend }}=0.009$ and $1.26(1.17,1.36), p_{\text {trend }}<0.0001$, respectively, for highest vs lowest quintile after adjustment for diabetes and dietary risk factors.

Additional analyses After stratification by BMI, the associations between type 2 diabetes and NEAP, PRAL and A:P were slightly stronger in participants with BMI $<25 \mathrm{~kg} / \mathrm{m}^{2}$ than in those who were overweight or obese but the difference did not reach statistical significance across strata $(\mathrm{HR}[95 \% \mathrm{CI}]$ for highest vs lowest quintile of NEAP was $1.33[1.13,1.57]$ for participants with BMI $<25 \mathrm{~kg} / \mathrm{m}^{2}, 1.24[1.12,1.38]$ for overweight participants and $1.14[0.96,1.35]$ for obese participants, $p_{\text {interaction }}=0.4237$; electronic supplementary material $[\mathrm{ESM}]$ Table 1). Also, stratification by smoking status and hypertension yielded comparable results (HR [95\% CI] for highest vs lowest quintile of NEAP was $1.23[1.10,1.39]$ for never smokers and $1.20[1.08,1.33]$ for ever smokers, $p_{\text {interaction }}=0.3272$, and 1.25 
Table 2 Association of type 2 diabetes mellitus with NEAP, PRAL and A:P

\begin{tabular}{|c|c|c|c|c|c|c|}
\hline $\mathrm{Model}^{\mathrm{a}}$ & Quintile 1 & Quintile 2 & Quintile 3 & Quintile 4 & Quintile 5 & $p_{\text {trend }}$ \\
\hline \multicolumn{7}{|l|}{ NHS } \\
\hline \multicolumn{7}{|l|}{ Dietary NEAP } \\
\hline No. of cases/person-years & $1051 / 342,428$ & $1373 / 341,989$ & $1598 / 341,556$ & $1699 / 341,826$ & $1934 / 341,838$ & \\
\hline Age-adjusted & 1.00 & $1.27(1.18,1.38)^{*}$ & $1.50(1.39,1.62)^{*}$ & $1.65(1.53,1.79)^{*}$ & $2.07(1.91,2.23)^{*}$ & $<0.0001$ \\
\hline Multivariate model 1 & 1.00 & $1.13(1.05,1.23)^{*}$ & $1.23(1.13,1.33)^{*}$ & $1.22(1.12,1.32)^{*}$ & $1.28(1.18,1.38)^{*}$ & $<0.0001$ \\
\hline Multivariate model 2 & 1.00 & $1.14(1.05,1.23)^{*}$ & $1.23(1.13,1.34)^{*}$ & $1.23(1.13,1.33)^{*}$ & $1.29(1.19,1.41)^{*}$ & $<0.0001$ \\
\hline \multicolumn{7}{|l|}{ Dietary PRAL } \\
\hline No. of cases/person-years & $1083 / 342,058$ & $1382 / 341,855$ & $1516 / 341,733$ & $1708 / 341,945$ & $1966 / 342,047$ & \\
\hline Age-adjusted & 1.00 & $1.27(1.17,1.37)^{*}$ & $1.42(1.31,1.54)^{*}$ & $1.67(1.31,1.54)^{*}$ & $2.15(1.99,2.32)^{*}$ & $<0.0001$ \\
\hline Multivariate model 1 & 1.00 & $1.13(1.04,1.22)^{*}$ & $1.17(1.08,1.27)^{*}$ & $1.21(1.12,1.31)^{*}$ & $1.26(1.16,1.36)^{*}$ & $<0.0001$ \\
\hline Multivariate model 2 & 1.00 & $1.10(1.02,1.20)^{*}$ & $1.14(1.05,1.24)^{*}$ & $1.18(1.09,1.28)^{*}$ & $1.23(1.13,1.33)^{*}$ & $<0.0001$ \\
\hline \multicolumn{7}{|l|}{ Dietary A:P } \\
\hline No. of cases/person-years & $1062 / 342,228$ & $1332 / 341,912$ & $1611 / 341,662$ & $1738 / 341,775$ & $1912 / 342,026$ & \\
\hline Age-adjusted & 1.00 & $1.23(1.14,1.34)^{*}$ & $1.51(1.40,1.63)^{*}$ & $1.70(1.57,1.83)^{*}$ & $2.08(1.93,2.25)^{*}$ & $<0.0001$ \\
\hline Multivariate model 1 & 1.00 & $1.10(1.01,1.19)^{*}$ & $1.21(1.12,1.31)^{*}$ & $1.22(1.13,1.32)^{*}$ & $1.26(1.16,1.36)^{*}$ & $<0.0001$ \\
\hline Multivariate model 2 & 1.00 & $1.11(1.02,1.20)^{*}$ & $1.23(1.13,1.34)^{*}$ & $1.26(1.15,1.37)^{*}$ & $1.31(1.19,1.43)^{*}$ & $<0.0001$ \\
\hline \multicolumn{7}{|l|}{ NHS2 } \\
\hline \multicolumn{7}{|l|}{ Dietary NEAP } \\
\hline No. of cases/person-years & $595 / 303,044$ & $752 / 302,999$ & $819 / 302,865$ & $904 / 302,564$ & $1039 / / 302,459$ & \\
\hline Age-adjusted & 1.00 & $1.32(1.19,1.47)^{*}$ & $1.57(1.41,1.75)^{*}$ & $1.98(1.78,2.19)^{*}$ & $2.82(2.54,3.12)^{*}$ & $<0.0001$ \\
\hline Multivariate model 1 & 1.00 & $1.03(0.93,1.15)$ & $1.07(0.96,1.19)$ & $1.14(1.03,1.27)^{*}$ & $1.30(1.17,1.44)^{*}$ & $<0.0001$ \\
\hline Multivariate model 2 & 1.00 & $1.01(0.91,1.13)$ & $1.04(0.93,1.16)$ & $1.10(0.98,1.23)$ & $1.22(1.09,1.37)^{*}$ & $<0.0001$ \\
\hline \multicolumn{7}{|l|}{ Dietary PRAL } \\
\hline No. of cases/person-years & $684 / 303,268$ & $806 / 303,105$ & $820 / 302,908$ & $861 / 302,517$ & $952 / 302,395$ & \\
\hline Age-adjusted & 1.00 & $1.34(1.21,1.48)^{*}$ & $1.57(1.42,1.74)^{*}$ & $1.95(1.76,2.16)^{*}$ & $2.83(2.55,3.13)^{*}$ & $<0.0001$ \\
\hline Multivariate model 1 & 1.00 & $1.13(1.02,1.25)^{*}$ & $1.11(1.00,1.23)^{*}$ & $1.17(1.05,1.30)^{*}$ & $1.33(1.20,1.48)^{*}$ & $<0.0001$ \\
\hline Multivariate model 2 & 1.00 & $1.10(0.99,1.22)$ & $1.07(0.96,1.19)$ & $1.30(1.00,1.24)^{*}$ & $1.25(1.12,1.40)^{*}$ & 0.0065 \\
\hline \multicolumn{7}{|l|}{ Dietary A:P } \\
\hline No. of cases/person-years & $563 / 302,924$ & $749 / 303,056$ & $839 / 302,969$ & $896 / 302,618$ & $1026 / 302,366$ & \\
\hline Age-adjusted & 1.00 & $1.37(1.22,1.52)^{*}$ & $1.69(1.51,1.88)^{*}$ & $2.06(1.85,2.29)^{*}$ & $3.07(2.77,3.41)^{*}$ & $<0.0001$ \\
\hline Multivariate model 1 & 1.00 & $1.08(0.97,1.21)$ & $1.09(0.97,1.21)$ & $1.18(1.06,1.32)^{*}$ & $1.35(1.21,1.50)^{*}$ & $<0.0001$ \\
\hline Multivariate model 2 & 1.00 & $1.07(0.95,1.20)$ & $1.06(0.95,1.19)$ & $1.15(1.02,1.29)^{*}$ & $1.30(1.15,1.47)^{*}$ & $<0.0001$ \\
\hline \multicolumn{7}{|l|}{ HPFS } \\
\hline \multicolumn{7}{|l|}{ Dietary NEAP } \\
\hline No. of cases/person-years & $585 / 160,351$ & $636 / 160,660$ & $701 / 160,617$ & $770 / 160,289$ & $849 / 159,654$ & \\
\hline Age-adjusted & 1.00 & $1.07(0.95,1.20)$ & $1.21(1.08,1.35)^{*}$ & $1.41(1.27,1.57)^{*}$ & $1.74(1.56,1.94)^{*}$ & $<0.0001$ \\
\hline Multivariate model 1 & 1.00 & $1.00(0.89,1.12)$ & $1.08(0.96,1.20)$ & $1.16(1.04,1.29)^{*}$ & $1.32(1.18,1.47)^{*}$ & $<0.0001$ \\
\hline Multivariate model 2 & 1.00 & $0.92(0.82,1.03)$ & $0.95(0.84,1.06)$ & $0.99(0.88,1.11)$ & $1.09(0.96,1.23)$ & 0.0370 \\
\hline \multicolumn{7}{|l|}{ Dietary PRAL } \\
\hline No. of cases/person-years & $585 / 160,199$ & $688 / 160,651$ & $694 / 160,536$ & $752 / 160,402$ & $825 / 159,773$ & \\
\hline Age-adjusted & 1.00 & $1.17(1.04,1.30)^{*}$ & $1.21(1.08,1.35)^{*}$ & $1.39(1.25,1.55)^{*}$ & $1.71(1.54,1.91)^{*}$ & $<0.0001$ \\
\hline Multivariate model 1 & 1.00 & $1.10(0.98,1.23)$ & $1.09(0.97,1.22)$ & $1.17(1.04,1.30)^{*}$ & $1.29(1.16,1.44)^{*}$ & $<0.0001$ \\
\hline Multivariate model 2 & 1.00 & $1.01(0.90,1.13)$ & $0.95(0.85,1.07)$ & $0.99(0.88,1.12)$ & $1.07(0.94,1.20)$ & 0.3583 \\
\hline \multicolumn{7}{|l|}{ Dietary A:P } \\
\hline No. of cases/person-years & $553 / 160,474$ & $633 / 160,629$ & $662 / 160,617$ & $816 / 160,334$ & $877 / 159,507$ & \\
\hline Age-adjusted & 1.00 & $1.1(1.02,1.28)^{*}$ & $1.22(1.09,1.37)^{*}$ & $1.60(1.44,1.79)^{*}$ & $1.94(1.74,2.16)^{*}$ & $<0.0001$ \\
\hline Multivariate model 1 & 1.00 & $1.04(0.92,1.16)$ & $1.03(0.92,1.15)$ & $1.26(1.12,1.40)^{*}$ & $1.39(1.25,1.55)^{*}$ & $<0.0001$ \\
\hline Multivariate model 2 & 1.00 & $0.94(0.84,1.06)$ & $0.90(0.80,1.01)$ & $1.07(0.94,1.20)$ & $1.15(1.01,1.31)^{*}$ & 0.0016 \\
\hline
\end{tabular}


Table 2 (continued)

\begin{tabular}{|c|c|c|c|c|c|c|}
\hline $\operatorname{Model}^{\mathrm{a}}$ & Quintile 1 & Quintile 2 & Quintile 3 & Quintile 4 & Quintile 5 & $p_{\text {trend }}$ \\
\hline \multicolumn{7}{|l|}{ Pooled cohorts } \\
\hline \multicolumn{7}{|l|}{ Dietary NEAP } \\
\hline Age-adjusted & 1.00 & $1.22(1.09,1.37)^{*}$ & $1.42(1.23,1.64)^{*}$ & $1.67(1.40,1.98)^{*}$ & $2.16(1.68,2.79)^{*}$ & $<0.0001$ \\
\hline Multivariate model 1 & 1.00 & $1.06(0.98,1.15)$ & $1.13(1.03,1.24)^{*}$ & $1.18(1.11,1.25)^{*}$ & $1.29(1.22,1.37)^{*}$ & $<0.0001$ \\
\hline Multivariate model 2 & 1.00 & $1.03(0.91,1.16)$ & $1.07(0.91,1.26)$ & $1.10(0.97,1.26)$ & $1.21(1.09,1.33)^{*}$ & $<0.0001$ \\
\hline \multicolumn{7}{|l|}{ Dietary PRAL } \\
\hline Age-adjusted & 1.00 & $1.26(1.17,1.35)^{*}$ & $1.39(1.22,1.60)^{*}$ & $1.66(1.39,1.97) *$ & $2.19(1.64,2.94)^{*}$ & $<0.0001$ \\
\hline Multivariate model 1 & 1.00 & $1.12(1.06,1.18)^{*}$ & $1.13(1.07,1.20)^{*}$ & $1.19(1.13,1.26)^{*}$ & $1.29(1.22,1.36)^{*}$ & $<0.0001$ \\
\hline Multivariate model 2 & 1.00 & $1.08(1.02,1.14)^{*}$ & $1.06(0.96,1.18)$ & $1.10(1.06,1.22)^{*}$ & $1.19(1.08,1.30)^{*}$ & 0.0093 \\
\hline \multicolumn{7}{|l|}{ Dietary A:P } \\
\hline Age-adjusted & 1.00 & $1.24(1.13,1.36)^{*}$ & $1.46(1.24,1.72)^{*}$ & $1.77(1.55,2.04)^{*}$ & $2.31(1.78,3.02)^{*}$ & $<0.0001$ \\
\hline Multivariate model 1 & 1.00 & $1.08(1.02,1.14)^{*}$ & $1.11(1.00,1.23)^{*}$ & $1.22(1.15,1.29)^{*}$ & $1.32(1.24,1.40)^{*}$ & $<0.0001$ \\
\hline Multivariate model 2 & 1.00 & $1.04(0.95,1.15)$ & $1.06(0.88,1.27)$ & $1.16(1.06,1.28)^{\mathrm{a}}$ & $1.26(1.17,1.36)^{*}$ & $<0.0001$ \\
\hline
\end{tabular}

Data are shown as HR $(95 \% \mathrm{CI})$. The results were pooled using random effect meta-analysis

${ }^{a}$ Multivariate model 1: additionally adjusted for total energy intake (quintiles), BMI (continuously), family history of diabetes (yes/no), menopausal status (premenopausal or postmenopausal, never, past or current menopausal hormone use), presence of hypertension and hypercholesterolaemia (yes/ no), smoking status (never smoker, former smoker, current smoker: 1-14, 15-24 or $\geq 25$ cigarettes/day), alcohol intake (0, 0.1-4.9, 5.0-14.9, 15.0-19.9, $20.0-29.9$ and $\geq 30 \mathrm{~g} /$ day $)$, moderate/vigorous intensity activity $(0,0.01-1.0,1.0-3.5,3.5-6.0$ and $\geq 6 \mathrm{~h} / \mathrm{week})$. Multivariate model 2 : additionally adjusted for glycaemic load (quintiles), AHEI index (quintiles; including the following components: sugar-containing beverages, fruit, vegetables, nuts, red meat, whole grains, EPA, DHA, other PUFAs, trans fat, and sodium) and the western dietary pattern (quintiles)

$* p<0.05$

$[1.15,1.36]$ for participants without hypertension and $1.17[0.99$, 1.38] for participants with hypertension, $p_{\text {interaction }}=0.8875$; ESM Table 1). In addition, no differential associations were found after stratification by history of kidney stones and age (HR [95\% CI] for highest vs lowest quintile of NEAP was $0.99[0.70,1.25]$ for those with kidney stones and $1.11[0.99,1.29]$ for those without kidney stones, $p_{\text {interaction }}=0.3089$, and $1.19[1.02,1.38]$ for participants below 60 years of age and $1.13[0.98,1.31]$ for those aged 60 years and above; ESM Table 1).

Results did not differ in sensitivity analyses using a 4 year lag of exposure to dietary acid load (HR [95\% CI] for highest vs lowest quintile of NEAP was $1.30[1.18,1.41], p_{\text {trend }}$ $<0.0001$ for NHS, 1.24 [1.10, 1.39], $p_{\text {trend }}<0.0001$ for NHS2 and $1.13[0.99,1.28], p_{\text {trend }}=0.0026$ for HPFS $)$. Additional adjustment for animal protein weakened the association between dietary NEAP and type 2 diabetes but results remained significant among women in NHS and NHS2 (HR [95\% CI] for highest vs lowest quintile was 1.23 [1.12, 1.34], $p_{\text {trend }}<0.0001$ for NHS, $1.14[1.01,1.29], p_{\text {trend }}=0.0103$ for NHS2 and $0.97[0.85,1.11], p_{\text {trend }}=0.8328$ for HPFS).

\section{Discussion}

In three prospective cohorts of men and women in the USA, we found that dietary acid load was associated with an increased risk of type 2 diabetes. In addition, differences in BMI and other dietary risk factors for type 2 diabetes, such as glycaemic load, the AHEI index and an a priori-defined western dietary pattern, did not fully explain the observed associations.

Comparison with other studies The results of this study are in line with results from the E3N-EPIC cohort study wherein dietary acid load was found to be associated with the risk of type 2 diabetes in a cohort of French women aged 50 years [18]. Another study revealed that dietary NEAP and PRAL were associated with insulin resistance and beta cell function in Japanese men and women aged 19-69 years, with the latter association being mainly present in normal-weight individuals [17]. Recent findings from The Japan Public Health Centerbased Prospective Study showed that PRAL but not NEAP was associated with the risk of type 2 diabetes only in Japanese men [20]. Moreover, the E3N-EPIC study found that the association between dietary acid load and type 2 diabetes was stronger in women with BMI $<25 \mathrm{~kg} / \mathrm{m}^{2}$, which is in line with our findings. In contrast, another study in communitydwelling older men (aged 70-71 years) did not confirm the aforementioned associations [19]. It has been proposed that these contrasting results may be due to differences in age distribution since the results from Akter et al showed that the association between dietary acid load and type 2 diabetes was mainly observed in younger individuals [20]. However, our stratified analyses did not reveal any significant effect modification by age on the association between dietary acid load and type 2 diabetes. We found that the association 
between diet acid load and diabetes risk was slightly stronger in women from the NHS than in men from the HPFS, suggesting that diet-dependent acid load may affect the development of type 2 diabetes in a sex-specific manner (e.g. due to differences in sex hormones, such as oestrogen, which may affect acid-base balance) [36].

Potential mechanisms Dietary acid load was determined by validated indices based on protein and potassium intake. We have previously shown that animal protein but not vegetable protein is associated with increased type 2 diabetes [8]. In this analysis, we found that the association between dietary NEAP and type 2 diabetes was explained by animal protein intake to some extent. Sulphur-containing amino acids, such as methionine and cysteine, are found in animal protein and are main determinants of acid load as sulfate is generated after their oxidation [37]. Some studies of animal protein in relation to type 2 diabetes have shown conflicting results [38]. Nevertheless, red meat intake, a major source of sulphurcontaining amino acids, has been consistently associated with an increased risk of insulin resistance, the metabolic syndrome and type 2 diabetes [39].

The main food sources of potassium are fruit and vegetables, which also provide other base cations (e.g. magnesium) [23]. A previous review showed that green leafy vegetable intake was associated with a reduced risk of type 2 diabetes but inconsistent results were found for intake of other vegetables and fruit [40]. Potassium is involved in acid-base balance by assisting electro-neutrality through exchange across cellular membranes for hydrogen ions [41, 42]. As a result, potassium-rich foods have been shown to be more alkalising than animal product-based foods [43].

The hypothesis that low-grade-metabolic acidosis may play a role in the aetiology of type 2 diabetes has been suggested by others. Some experimental studies have shown that reduction of the extracellular $\mathrm{pH}$ decreases beta cell response [44], reduces insulin secretion [44] and increases cortisol production [45], which in turn may affect the development of type 2 diabetes [46]. In addition, several studies have confirmed that markers of low-grade metabolic acidosis, such as lower plasma bicarbonate $[6,15,16]$, higher anion gap [15], lower urine $\mathrm{pH}$ [47] and high levels of plasma lactate [48], are linked to insulin resistance, suggesting that low-grade metabolic acidosis could be involved in the aetiology of type 2 diabetes.

Methodological considerations Strengths of this study include the prospective design with long follow-up, the large sample size, high rates of follow-up and repeated dietary measurements during follow-up. In addition, the wide range of data on confounding variables and the homogeneity of the study population help to reduce residual confounding. However, several limitations need to be considered. First, dietary data was based on self-reported FFQs. While these are susceptible to measurement error, we used energy-adjusted nutrient intake for the calculation of dietary acid load as well as repeated measurements of diet, which can reduce the magnitude of measurement error [49]. Nonetheless, phosphorus intake for the calculation of PRAL did not include the assessment of phosphorus-containing food additives. Although the results for PRAL were similar to those for NEAP and A:P, they should be interpreted with caution. Second, we did not have data on kidney function available in the cohorts. Since kidney function is an important determinant of acid-base balance [27], it may be speculated that the relationship between dietary acid load and type 2 diabetes is more pronounced in participants with impaired kidney function due to altered haemodynamic adaptation to high acid load [10]. Hence, future studies on dietary acid load that include detailed urinary markers of acid-base balance (e.g. ammonium) and kidney function are needed to clarify the observed associations. Third, this study is of an observational nature. Although we adjusted for many confounders, residual confounding cannot be fully excluded. Last, the study population consisted primarily of white health professionals. This may limit the generalisability of our study results but could strengthen internal validity since confounding by ethnicity and socioeconomic status is greatly reduced.

Public health implications It has recently been demonstrated in healthy individuals that both the capillary and urine $\mathrm{pH}$ can be modified by a diet high or low in protein combined with a high or low intake of fruit and vegetables [43]. Therefore, our findings may have important public health implications for the future. If future studies confirm that food-induced improvement in acid-base balance is accompanied by improved insulin sensitivity, this may facilitate development of dietary guidelines, such as more specific recommendations on the ratio of potassium to protein in diets.

Conclusions Findings from this prospective study in men and women suggest that a higher dietary acid load is associated with an increased risk of type 2 diabetes. These results are not fully explained by BMI or diet-related risk factors associated with type 2 diabetes, such as glycaemic index and overall healthy or western dietary patterns. Randomised controlled trials are needed to clarify whether specific dietary interventions to reduce dietary acid load (e.g. a diet high in fruit and vegetables and low in animal protein) could improve glucose homeostasis and reduce the risk of type 2 diabetes.

Funding The NHS and HPFS are supported by National Institutes of Health grants U54CA155626, P30DK46200, DK58845, UM1CA186107, UM1CA176726 and UM1CA167552. JCKdJ received the Albert Renold Travel Fellowship grant of the European Foundation for the Study of Diabetes (EFSD) and the Aspasia fund from the Netherlands Organization of Scientific Research (NWO) to perform this study. 
Duality of interest $\mathrm{OHF}$ and JCKdJ work in ErasmusAGE, a centre for ageing research across the life course, which received funding from Nestlé Nutrition (Nestec Ltd), Metagenics Inc. and AXA. None of the funding sources had a role in the study design; in the collection, analysis, and interpretation of data; in the writing of the report; or in the decision to submit the article for publication. All other authors declare that there is no duality of interest associated with their contribution to this manuscript.

Contribution statement JCKdJ, YL and FBH made a substantial contribution to conception and design. Data was acquired by YL, MC, VSM, JM, JPF and GCC and analysed and interpreted by JCKdJ, YL, MC, VSM, GCC, JPF, OHF and FBH. JCKdJ, YL and FBH drafted the article and MC, VSM, GCC, JPF, JM and OHF critically revised the manuscript for important intellectual content. All authors approved the final manuscript to be published. FBH is guarantor of this work.

Open Access This article is distributed under the terms of the Creative Commons Attribution 4.0 International License (http:// creativecommons.org/licenses/by/4.0/), which permits unrestricted use, distribution, and reproduction in any medium, provided you give appropriate credit to the original author(s) and the source, provide a link to the Creative Commons license, and indicate if changes were made.

\section{References}

1. Hu FB (2011) Globalization of diabetes: the role of diet, lifestyle, and genes. Diabetes Care 34:1249-1257

2. Ley SH, Ardisson Korat AV, Sun Q et al (2016) Contribution of the Nurses Health Studies to uncovering risk factors for type 2 diabetes: diet, lifestyle, biomarkers, and genetics. Am J Public Health 106:1624-1630

3. Estruch R, Martinez-Gonzalez MA, Corella D et al (2009) Effects of dietary fibre intake on risk factors for cardiovascular disease in subjects at high risk. J Epidemiol Community Health 63:582-588

4. Bo S, Ciccone G, Guidi S et al (2008) Diet or exercise: what is more effective in preventing or reducing metabolic alterations? Eur J Endocrinol 159:685-691

5. Adeva MM, Souto G (2011) Diet-induced metabolic acidosis. Clin Nutr 30:416-421

6. Mandel EI, Taylor EN, Curhan GC (2013) Dietary and lifestyle factors and medical conditions associated with urinary citrate excretion. Clin J Am Soc Nephrol 8:901-908

7. van Nielen M, Feskens EJ, Mensink M et al (2014) Dietary protein intake and incidence of type 2 diabetes in Europe: the EPICInterAct Case-Cohort Study. Diabetes Care 37:1854-1862

8. Malik VS, Li Y, Tobias DK, Pan A, Hu FB (2016) Dietary protein intake and risk of type 2 diabetes in US men and women. Am J Epidemiol 183:715-728

9. Lemann J Jr (1999) Relationship between urinary calcium and net acid excretion as determined by dietary protein and potassium: a review. Nephron 81(Suppl 1):18-25

10. Scialla JJ (2015) The balance of the evidence on acid-base homeostasis and progression of chronic kidney disease. Kidney Int 88:9-11

11. Scialla JJ, Anderson CA (2013) Dietary acid load: a novel nutritional target in chronic kidney disease? Adv Chronic Kidney Dis 20:141-149

12. Engberink MF, Bakker SJ, Brink EJ et al (2012) Dietary acid load and risk of hypertension: the Rotterdam Study. Am J Clin Nutr 95: $1438-1444$
13. Zhang L, Curhan GC, Forman JP (2009) Diet-dependent net acid load and risk of incident hypertension in United States women. Hypertension 54:751-755

14. Remer T, Krupp D, Shi L (2014) Dietary protein's and dietary acid load's influence on bone health. Crit Rev Food Sci Nutr 54:1140 1150

15. Farwell WR, Taylor EN (2008) Serum bicarbonate, anion gap and insulin resistance in the National Health and Nutrition Examination Survey. Diabet Med 25:798-804

16. Mandel EI, Curhan GC, Hu FB, Taylor EN (2012) Plasma bicarbonate and risk of type 2 diabetes mellitus. CMAJ 184:E719-E725

17. Akter S, Eguchi M, Kuwahara K et al (2016) High dietary acid load is associated with insulin resistance: the Furukawa Nutrition and Health Study. Clin Nutr 35:453-459

18. Fagherazzi G, Vilier A, Bonnet F et al (2014) Dietary acid load and risk of type 2 diabetes: the E3N-EPIC cohort study. Diabetologia 57:313-320

19. Xu H, Jia T, Huang X et al (2014) Dietary acid load, insulin sensitivity and risk of type 2 diabetes in community-dwelling older men. Diabetologia 57:1561-1568

20. Akter S, Kurotani K, Kashino I et al (2016) High dietary acid load score is associated with increased risk of type 2 diabetes in Japanese men: the Japan Public Health Center-based Prospective Study. J Nutr 146:1076-1083

21. Willett WC, Sampson L, Browne ML et al (1988) The use of a selfadministered questionnaire to assess diet four years in the past. Am J Epidemiol 127:188-199

22. Rimm EB, Giovannucci EL, Stampfer MJ, Colditz GA, Litin LB, Willett WC (1992) Reproducibility and validity of an expanded self-administered semiquantitative food frequency questionnaire among male health professionals. Am J Epidemiol 135:1114 1126, discussion 1127-1136

23. Department of Agriculture ARS (2001) Nutrient Database for Standard Reference, release 14, https://ndb.nal.usda.gov/ndb/, accessed 1 Nov 2014

24. Frassetto LA, Todd KM, Morris RC Jr, Sebastian A (1998) Estimation of net endogenous noncarbonic acid production in humans from diet potassium and protein contents. Am J Clin Nutr 68:576-583

25. Remer T, Manz F (1995) Potential renal acid load of foods and its influence on urine pH. J Am Diet Assoc 95:791-797

26. Zwart SR, Hargens AR, Smith SM (2004) The ratio of animal protein intake to potassium intake is a predictor of bone resorption in space flight analogues and in ambulatory subjects. Am J Clin Nutr 80:1058-1065

27. Breslau NA, Brinkley L, Hill KD, Pak CY (1988) Relationship of animal protein-rich diet to kidney stone formation and calcium metabolism. J Clin Endocrinol Metab 66:140-146

28. Willett WC, Howe GR, Kushi LH (1997) Adjustment for total energy intake in epidemiologic studies. Am J Clin Nutr 65: 1220S-1228S, discussion 1229S-1231S

29. National Diabetes Data Group (1979) Classification and diagnosis of diabetes mellitus and other categories of glucose intolerance. Diabetes 28:1039-1057

30. The Expert Committee on the Diagnosis and Classification of Diabetes Mellitus (1997) Report of the expert committee on the diagnosis and classification of diabetes mellitus. Diabetes Care 20:1183-1197

31. Manson JE, Rimm EB, Stampfer MJ et al (1991) Physical activity and incidence of non-insulin-dependent diabetes mellitus in women. Lancet 338:774-778

32. Hu FB, Leitzmann MF, Stampfer MJ, Colditz GA, Willett WC, Rimm EB (2001) Physical activity and television watching in relation to risk for type 2 diabetes mellitus in men. Arch Intern Med 161:1542-1548 
33. Chiuve SE, Fung TT, Rimm EB et al (2012) Alternative dietary indices both strongly predict risk of chronic disease. J Nutr 142: 1009-1018

34. Hu FB, Rimm E, Smith-Warner SA et al (1999) Reproducibility and validity of dietary patterns assessed with a food-frequency questionnaire. Am J Clin Nutr 69:243-249

35. Willett W, Manson J, Liu S (2002) Glycemic index, glycemic load, and risk of type 2 diabetes. Am J Clin Nutr 76:274S-280S

36. Orr-Walker BJ, Horne AM, Evans MC et al (1999) Hormone replacement therapy causes a respiratory alkalosis in normal postmenopausal women. J Clin Endocrinol Metab 84:1997-2001

37. Patience JF (1990) A review of the role of acid-base balance in amino acid nutrition. J Anim Sci 68:398-408

38. Rietman A, Schwarz J, Tome D, Kok FJ, Mensink M (2014) High dietary protein intake, reducing or eliciting insulin resistance? Eur J Clin Nutr 68:973-979

39. Micha R, Wallace SK, Mozaffarian D (2010) Red and processed meat consumption and risk of incident coronary heart disease, stroke, and diabetes mellitus: a systematic review and meta-analysis. Circulation 121:2271-2283

40. Carter P, Gray LJ, Troughton J, Khunti K, Davies MJ (2010) Fruit and vegetable intake and incidence of type 2 diabetes mellitus: systematic review and meta-analysis. BMJ 341:c4229

41. Adrogue HJ, Madias NE (1981) Changes in plasma potassium concentration during acute acid-base disturbances. Am J Med 71:456-467
42. Aronson PS, Giebisch G (2011) Effects of $\mathrm{pH}$ on potassium: new explanations for old observations. J Am Soc Nephrol 22:1981-1989

43. Hietavala EM, Stout JR, Hulmi JJ et al (2015) Effect of diet composition on acid-base balance in adolescents, young adults and elderly at rest and during exercise. Eur J Clin Nutr 69:399-404

44. Rebolledo OR, Hernandez RE, Zanetta AC, Gagliardino JJ (1978) Insulin secretion during acid-base alterations. Am J Physiol 234: E426-E429

45. Maurer M, Riesen W, Muser J, Hulter HN, Krapf R (2003) Neutralization of Western diet inhibits bone resorption independently of $\mathrm{K}$ intake and reduces cortisol secretion in humans. Am J Physiol Renal Physiol 284:F32-F40

46. Bose M, Olivan B, Laferrere B (2009) Stress and obesity: the role of the hypothalamic-pituitary-adrenal axis in metabolic disease. Curr Opin Endocrinol Diabetes Obes 16:340-346

47. Maalouf NM, Cameron MA, Moe OW, Adams-Huet B, Sakhaee K (2007) Low urine $\mathrm{pH}$ : a novel feature of the metabolic syndrome. Clin J Am Soc Nephrol 2:883-888

48. Williams RS, Heilbronn LK, Chen DL, Coster AC, Greenfield JR, Samocha-Bonet D (2016) Dietary acid load, metabolic acidosis and insulin resistance - Lessons from cross-sectional and overfeeding studies in humans. Clin Nutr 35:1084-1090

49. Hu FB, Stampfer MJ, Rimm E et al (1999) Dietary fat and coronary heart disease: a comparison of approaches for adjusting for total energy intake and modeling repeated dietary measurements. Am J Epidemiol 149:531-540 